\title{
Imunoblot como teste suplementar para detecção de anticorpos contra o vírus da hepatite $\mathrm{C}$ em doadores de sangue
}

\author{
Immunoblot as a supplemental test to detect antibodies \\ to hepatitis $\mathrm{C}$ virus in blood donors
}

\author{
Francisco José Dutra Souto1, Luciano Côrrea Ribeiro1, Gustavo Faria Perazolo1, \\ Hildenete Monteiro Fortes ${ }^{1,2}$ and Alzira Almeida Saldanha ${ }^{2}$
}

\begin{abstract}
Resumo Testes suplementares para melhorar a especificidade do anti-VHC por ELISA nos bancos de sangue não são oficialmente recomendados no Brasil. No intuito de avaliar a taxa de falso-positivos, 70 doadores com transaminases normais e anti-VHC por ELISA foram submetidos a imunoblot de $3^{a}$ geração no Hemocentro de Mato Grosso, que não dispõe da técnica da reação de cadeia de polimerase. O teste confirmou o anti-VHC em $44(62,9 \%)$, sendo negativo em $22(31,4 \%)$ e indeterminado em $4(5,7 \%)$. Confirmação pelo imunoblot ajuda a identificar os testes ELISA que são falso-positivos, tranqüilizando o grande contingente de doadores nessa situação e separando os que necessitam de acompanhamento médico. Com esse objetivo, sugere-se que o imunoblot poderia ser útil nos bancos de sangue brasileiros que não contam com técnicas de Biologia Molecular.
\end{abstract}

Palavras-chaves: Hepatite C. Anti-VHC. Immunoblot. Falso-positivo.

Abstract Supplemental tests using Immunoblot are recommended to improve specificity of anti-HCV by ELISA. In Brazil immunoblot is not officially recommended. Aiming to identify EIA false-positive rate 70 positive EIA anti-HCV blood donors were submitted to $3^{\text {rd }}$ generation immunoblot at Hemocentro of Mato Grosso State where polymerase chain reaction tests are not performed. There were 44 (62.9\%) immunoblot-positive, 22 (31.4\%) negative and 4 (5.7\%) indeterminate. Anti-HCV immunoblot can distinguish blood donors with falsepositive ELISA from those who need medical assessment. Our data suggest that immunoblot could be useful in Brazilian blood banks where molecular biology tests are not available.

Key-words: Hepatitis C. Anti-HCV. Recombinant immunoblot False-positive.

Anticorpos contra o vírus da hepatite C (anti-VHC) são pesquisados em todos os candidatos a doação de sangue através de teste imuno-enzimático (ELISA). Este teste tem alta sensibilidade, detectando praticamente todos os portadores do vírus, além de indivíduos que foram infectados e não desenvolveram a infecção espontaneamente, tendo apenas anticorpos ${ }^{6}$. No entanto, em populações de baixo risco, como doadores de sangue e população geral, o teste tem baixo valor preditivo positivo, gerando exames falso-positivos em pessoas que nunca foram expostas ao vírus da hepatite $\mathrm{C}(\mathrm{VHC})^{2}$.

Indivíduos com anti-VHC positivo e aminotransferases normais apresentam maior possibilidade de terem testes ELISA falso-positivos ${ }^{2}$. Neste caso, são recomendados testes suplementares para aumentar a especificidade do $E_{\text {EISA }}{ }^{13}$. O mais utilizado é o imunoblot (RIBA) de $2^{\mathrm{a}}$ ou $3^{\text {a }}$ geração, que detecta reação do soro do indivíduo contra proteínas de até 4 regiões diferentes do genoma do $\mathrm{VHC}^{7}$. Quando não há reação a qualquer desses antígenos o teste é considerado negativo. Quando há reação a apenas uma proteína, indeterminado. No caso de reação a duas bandas do RIBA ou mais, a positividade do ELISA anti-VHC é confirmada. Este teste não serve para detectar viremia, uma vez que indivíduos com infecção resolvida continuam a produzir anticorpos anti-VHC por tempo indeterminado. Sendo assim, a única utilidade desse teste concentra-se na diferenciação de indivíduos com testes falso-positivos daqueles que necessitarão de investigação clínica ${ }^{4}$. Nos Estados Unidos, com o uso do RIBA, estima-se que $40 \%$ dos doadores com anti-VHC positivo por ELISA têm exames falso-positivos ${ }^{2}$.

1. Núcleo de Estudos de Doenças Infecciosas e Tropicais de Mato Grosso da Universidade Federal de Mato Grosso; 2 . Hemocentro Coordenador de Mato Grosso, Cuiabá; MT.

Endereço para correspondência: Dr. Francisco José Dutra Souto. Hospital Júlio Muller. Rua L, s/n, Jardim Alvorada, 78048-790 Cuiabá, MT, Brasil.

Telefax: 55-65-6157302,

e-mail: fsouto@terra.com.br

Recebido para publicação em 10/10/2000. 
No Brasil, o Ministério da Saúde não indica aos bancos de sangue que realizem qualquer investigação de doadores com anti-VHC por ELISA, recomendando que sejam encaminhados para atendimento médico ${ }^{5}$. Alguns bancos de sangue públicos das regiões mais desenvolvidas do país contam com técnicas sofisticadas de biologia molecular para detecção do material genômico do VHC. Esta não é a realidade da maioria dos bancos de sangue públicos e privados do país, como por exemplo, o Hemocentro do Estado de Mato Grosso. Nesta instituição, a solução encontrada para tentar distinguir os exames falso-positivos, orientando o doador com anti-VHC positivo por ELISA, foi a introdução do RIBA ocorrida em 1997.

Com o intuito de averiguar a taxa de anti-VHC falsopositivo por ELISA em nosso meio, realizamos levantamento de todos os resultados de RIBA entre doadores com dois ELISA anti-VHC positivos, no período de janeiro de 1998 a maio de 2000 no Hemocentro de Mato Grosso.

No período do estudo ocorreram cerca de 11.000 doações. A prevalência de anti-VHC ELISA positivos variou mensalmente entre $0,5 \%$ a $1 \%$. A maioria desses doadores foi submetida a nova avaliação laboratorial. No total, 70 doadores com anti-VHC tiveram o ELISA positivo nesta segunda amostra. As aminotransferases foram normais na grande maioria desses indivíduos. Esta mesma amostra era então submetida a teste suplementar, para o que se utilizou RIBA comercial de $3^{\mathrm{a}}$ geração, contendo antígenos recombinantes representativos das regiões central, NS3, NS4 e NS5 do genoma viral. Dos 70 doadores, $44(62,9 \%)$ confirmaram positividade do antiVHC pelo RIBA, quatro $(5,7 \%)$ tiveram testes indeterminados e $22(31,4 \%)$ foram negativos.

Analisou-se a diferença média entre a densidade óptica e o cut off das leituras de ELISA dos grupos RIBA positivo e RIBA negativo. Os valores encontrados foram significativamente mais elevados entre os positivos (2.376 vs. $1.235 ;$ t de Student $=4,8 ; p<0,001$ ). No entanto, houve grande dispersão dos resultados, impedindo a valorização isolada da leitura do ELISA (Figura 1).

A utilização do RIBA permitiu que $31,4 \%$ dos doadores anti-VHC ELISA positivos fossem tranqüilizados e orientados sem necessidade de

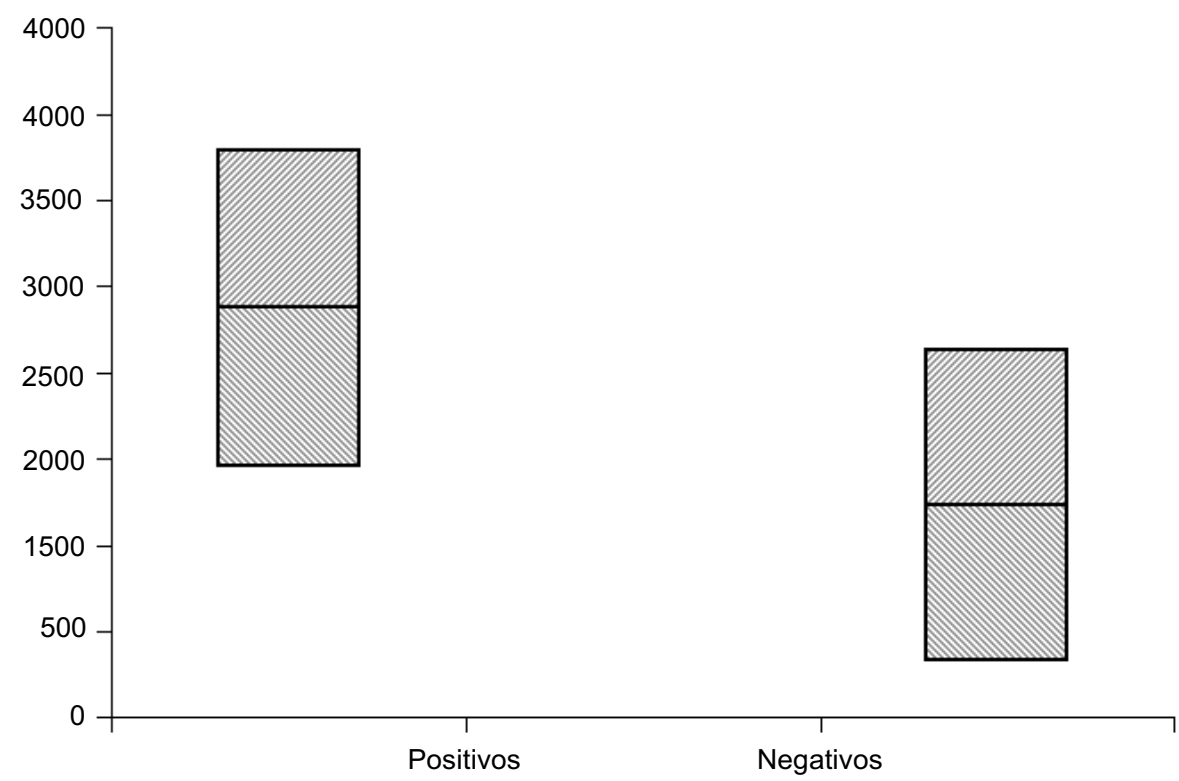

Figura 1 - Médias, desvios-padrão e valores extremos das diferenças entre absorbância e cut off das leituras de ELISA anti-VHC nos grupos com imunoblot (RIBA) positivo e negativo.

maiores investigações e incômodos. Estes números são semelhantes aos relatados nos Estados Unidos, onde o imunoblot é recomendado para aumentar especificidade do anti-VHC em grupos de baixo risco $^{26}$ 7. Os pacientes com RIBA positivo ou indeterminado deverão ser encaminhados para avaliação médica e pesquisa do RNA do VHC. Como a resolução espontânea da infecção pelo VHC acontece na minoria dos indivíduos, a confirmação da presença de anticorpos é forte indicação da presença do $\mathrm{VHC}^{14}$.

Este resultado sugere que se considere, em bancos de sangue no Brasil, a realização do RIBA em indivíduos com anti-VHC por ELISA, aminotransferases normais e sem fator de risco. Tal conduta diminuiria a ansiedade gerada com o falso diagnóstico de infecção pelo VHC. Por outro lado, pode ser mais fácil implementar este 
método do que testes de biologia molecular em regiões com dificuldades de recursos técnicos e econômicos.

Nossos dados sugerem que é importante confirmar o anti-VHC através do RIBA nos estudos de prevalência em comunidades de baixo risco, como a população geral, para confirmação de anticorpos detectados por ELISA. Grande parte dos dados sobre prevalência de anti-VHC no Brasil leva em consideração apenas dados de ELISA, gerando provável superestimativa. Estudos de prevalência do VHC devem sempre considerar a confirmação dos ELISA positivos pelo RIBA.

\section{REFERÊNCIAS BIBLIOGRÁFICAS}

1. Alter HJ, Seef LB. Recovery, persistence, and sequelae in hepatitis $C$ infection: a perspective on long-term outcome. Seminars in Liver Disease 20:17-35, 2000.

2. Atrah HI, Hutchinson F, Gough D, Ala FA, Ahmed MM. Hepatitis $C$ virus seroconversion rate in established blood donors. Journal of Medical Virology 46:329-333, 1995.

3. Center for Disease Control. Recommendations for prevention and control of hepatitis $\mathrm{C}$ virus infection and $\mathrm{HCV}$-related chronic disease. MMWR 47: RR-19, 1998.

4. Damen M, Zaaijer HL, Cuypers HTM, Vrielink H, van der Poel $\mathrm{CL}$, Reesink HW, Lelie PN. Reliability of the third generation immunoblot assay for hepatitis C virus. Transfusion 35:745-749, 1995.

5. Fundação Nacional de Saúde, Centro Nacional de Epidemiologia, Ministério da Saúde. Guia de vigilância epidemiológica, 1998.

6. Gretch DR. Use and interpretation of HCV diagnosis tests in the clinical setting. Clinics in Liver Disease 1: 543-558, 1997.

7. Morishima C, Gretch DR. Clinical use of hepatitis $C$ virus tests for diagnosis and monitoring during therapy. Clinics in Liver Disease 3: 717-740, 1999. 